\title{
Exposure of several Belgian consumer groups to pesticide residues through fresh fruit and vegetable consumption
}

\author{
Wendie L. Claeys ${ }^{\mathrm{a}}$, Jean-François Schmit ${ }^{\mathrm{a}}$, Claude Bragard ${ }^{\mathrm{b}, \mathrm{c}}$, Guy Maghuin-Rogister $^{\mathrm{b}, \mathrm{d}}$, Luc Pussemier ${ }^{\mathrm{b}, \mathrm{e}}$, Bruno \\ Schiffers ${ }^{\mathrm{b}, \mathrm{f}}$ \\ ${ }^{a}$ DG Policy Control, Federal Agency for the Safety of the Food Chain (FASFC), Brussels, Belgium \\ ${ }^{\mathrm{b}}$ Scientific Committee, Federal Agency for the Safety of the Food Chain (FASFC), Brussels, Belgium \\ ${ }^{\mathrm{c}}$ Earth \& Life Institute, Applied Microbiology—Phytopathology, Louvain-la-Neuve, Belgium \\ ${ }^{\mathrm{d}}$ Faculty of Veterinary Medicine, University of Liège, Belgium \\ ${ }^{\mathrm{e}}$ Veterinary and Agrochemical Research Centre (CODA-CERVA), Tervuren, Belgium \\ ${ }_{\mathrm{f}}^{\mathrm{f}}$ Gembloux Agro-Bio Tech, University of Liège, Belgium
}

\begin{abstract}
The output of a pesticide surveillance program (detection frequency and number of exceeding measures) can lead to unnecessary concern among consumers since they lack information concerning the actual exposure. In this study, the exposure to pesticide residues through fruit and vegetable consumption is evaluated based on the 2008 surveillance data of the Belgian Federal Agency for the Safety of the Food Chain (FASFC).

Results (deterministic and probabilistic approach) demonstrate that the chronic exposure of the adult population (>15 years) is generally under control, even at high or frequent consumption of fruit and vegetables. For most of the pesticide residues studied, the exposure is one hundred times lower than the 'acceptable daily intake' or ADI. With regard to children (2-5 years) who consume regularly or large amounts of fruit and vegetables, there are however, indications that for some pesticides the ADI can be exceeded. Nevertheless, due to the large uncertainty in these calculations, a more detailed study is required for this vulnerable group of consumers. In addition, it was demonstrated that washing and peeling of fruit and vegetables result in an exposure that is probably five to six times lower.
\end{abstract}

Keywords : Pesticides ; Exposure assessment ; Fruit ; Vegetables

\section{Introduction}

Pesticides are widely used to ensure high crop yields. In 2003, the sales of plant protection products (sum of fungicides, herbicides, insecticides and other pesticides) in agriculture amounted to around 9776 tonnes of active ingredient in Belgium (327,642 tonnes of active ingredient in the EU15 area in 2001) (Eurostat, 2009). Unlike most other chemical products, pesticides are deliberately released into the environment for controlling undesired organisms such as weeds, fungi and insects. Pesticides are biologically active compounds with a component specific inherent toxicity. They are regarded as significant sources of diffuse pollution that might cause longterm health implications in humans.

In general, food is the main exposure route. Exposure to pesticide residues through the diet is assumed to be five orders of magnitude higher than other exposure routes, such as air and drinking water (Juraske, Mutel, Stoessel, \& Hellweg, 2009). According to the World Health Organization (WHO), food consumption consists on average for $30 \%$ (based on mass) of fruit and vegetables, and fruit and vegetables are the most frequently consumed food group (WHO, 2003). Furthermore, because fruit and vegetables are mainly consumed raw or semi-processed, it is expected that they contain higher pesticide residue levels compared to other food groups of plant origin, such as bread and other foodstuffs based on cereal processing. In addition, it is well known that animal products are less contaminated by currently registered agricultural pesticides (see for example MAFF, 2000).

Given the potential risk of pesticides for public health, the use of pesticides in agriculture is subjected to constant monitoring. The surveillance focuses on the proper use of pesticides in terms of authorization and registration 
(application rates and pre-harvested intervals), and on compliance with maximum residue limits or MRLs. Although the surveillance output (detection frequency, percentage of samples exceeding the MRL) gives a good indication, it lacks the information necessary for a proper interpretation and objectification in terms of food safety. To evaluate the safety of consumers regarding pesticide residues, the exposure needs to be assessed and compared to health safety limits or toxicological endpoint values such as the ADI (acceptable daily intake) and the ARfD (acute reference dose). Whereas the MRL is a product limit and is based on the application of pesticides on crops according to Good Agricultural Practices (GAP) in controlled field experiments, health safety limits or toxicological endpoint values are based on toxicological data and insights. Exposure or intake of a compound below its health safety limit, is considered to be safe. As such, the residue concentration may be above the MRL without representing a risk to the consumer.

In the present study, the daily intake of pesticides of the Belgian population through fruit and vegetable consumption is evaluated in detail. Calculations are based on the results of the surveillance program 2008 of the Belgian Federal Agency for the Safety of the Food Chain (FASFC, 2008).

\section{Materials and methods}

\subsection{Pesticide residue data}

The 2008 FASFC surveillance program included 1413 samples of fruit and vegetables, in which 349 different pesticides were analysed. Of the 349 analysed pesticides, 138 were detected at least once (FASFC, 2008).

The FASFC surveillance program does not provide a full random analysis, but is based on a risk assessment (Maudoux et al., 2006). Several factors are considered including the importance of the food commodity in the diet, the percentage of exceeding measures observed in previous years, RASFF messages (European Rapid Alert System for Food and Feed), the toxicity of pesticides, and pesticides authorized in Belgium. Sampling is performed according to Directive 2002/63/EC (European Community, 2002) at border inspection posts (seaports, airports), auctions, importers, wholesalers, processors and to a lesser extent in retail. Samples are analysed in four officially recognised laboratories accredited following ISO 17025 (FASFC, 2008).

\subsection{Food consumption data}

Consumption data are obtained from the Belgian nation-wide food consumption survey (BFCS) performed in 2004 by the Belgian Institute for Public Health (Devriese et al., 2005). The survey included 3214 participants over 15 years old, which were interviewed twice about their consumption during the last $24 \mathrm{~h}$ (repeated nonconsecutive $24 \mathrm{~h}$ recall) in combination with a self-administered food frequency questionnaire. The fieldwork was spread over one year to anticipate seasonal effects and was carried out by trained dieticians. The selection of interviewed people and the moment of the interview were chosen in order to obtain a representative consumption profile of the Belgian population over 1 year anticipating seasonal effects.

A selection was made of food commodities recorded in the BFSC and certain commodities were combined as a group (e.g. consumption data on Chinese, Savoy, red and white cabbage, and sauerkraut were aggregated into the group 'cabbage') in order to match the commodities analysed in the FASFC pesticide surveillance campaign.

The total data set, including zero intakes ('zero consumption days'), was used as part of an 'average' diet for longterm consumer exposure assessment since the main interest of this study is to evaluate the probability that the ADI is exceeded. When one is however interested in assessing the safety of actually eating a commodity, it is preferred to use the 'consumers only' approach (Hamilton et al., 2004; Pieters, Ossendorp, \& Slob, 2005).

\subsection{Estimation of exposure}

The dietary exposure to pesticides ( $\mathrm{mg} \mathrm{kg}$ body weight $^{-1}$ day $^{-1}$ ) was calculated deterministically based on consumption data and individual body weights of the BFCS (Devriese et al., 2005), and residue monitoring data of the Belgian FASFC 2008 surveillance program (FASFC, 2008). For a given residue/food combination, the average residue concentration was multiplied with the average consumption as well as with the 97.5 th percentile (P97.5) of consumption in order to have an idea of the chronic exposure of the population to pesticide residues.

In a second phase, the exposure of a number of pesticides was evaluated in more detail by a probabilistic approach. Hereto, the Monte Carlo technique was applied. This technique involves the random sampling of each probability distribution within the model to produce hundreds or even thousands of scenarios (also called 
iterations or trials). Each probability is sampled in a manner that reproduces the distribution's shape. The distribution of the values calculated for the model outcome therefore reflects the probability of the values that could occur (Vose, 2006). Monte Carlo simulations were performed with 100,000 iterations. The model input distributions were randomly sampled by Latin Hypercube sampling. Calculations were performed by means of the commercially available software package @ Risk (Palisade Corporation, Version 5.0, NY, USA).

In order to have a good representation of consumption and pesticide residue data, both parametric and nonparametric approaches were evaluated. Fitting of probability distributions to the data in the parametric approach was performed using BestFit (Palisade, NY, USA). However, due to the large number of zero consumption days and of 'non-detects' in the residue concentration data, preference was given to the non-parametric approach. As such, model inputs (consumption and pesticide residue concentration data) were described by a discrete, uniform distribution. In this non-parametric approach the collected data points themselves are considered to form the distribution function and all possible values have the same probability of occurrence (Vose, 2006).

\section{Results}

\subsection{Pesticide monitoring data 2008}

Pesticide residues that were detected most frequently in fresh fruit and vegetables on the Belgian market in 2008, are the fungicides iprodione, boscalid, dithiocarbamates, imazalil, difenocona-zole, propamocarb, cyprodinil and thiabendazole. Residues were detected (i.e. result >LOQ) in approximately $72 \%$ of the samples and approximately $94 \%$ of the samples were compliant (i.e. result <LOQ or no violation of the MRL).

The main fruit groups for which residue levels exceeded the MRL, are exotic fruits (passion fruit), citrus fruit (oranges) and berries and small fruits (currants and strawberries). The main groups of vegetables showing MRL exceeding measures are fruiting vegetables (Chili peppers, eggplants, melons and lauki), bulb vegetables (garlic) and legume vegetables (beans).

Fruit and vegetables imported from outside the European Community showed relatively more MRL exceeding measures than fruit and vegetables originating from Member States (10.5\% compared to 3.7\% for Belgium and $3.1 \%$ for other Member States).

\subsection{Pesticide exposure assessment}

As a first screening, the exposure to pesticide residues was calculated by a deterministic approach on a total of 29 residues. These residues were selected out of the 349 analysed residues based on their detection frequency (at least $2 \%$ of the analysed samples having a result $>$ LOQ) and their representativeness (i.e. a sufficient number of samples was analysed). To take the variation of the concentrations into account, the residue concentration in the food was assumed to be equal to the average analytical result obtained for that food. A rough estimate of the total exposure to a given pesticide residue $\mathrm{X}$ was obtained by summing exposures from all residue $\mathrm{X} /$ food combinations considered. The total exposure was compared with the ADI and expressed in terms of \% ADI. For this conservative exposure estimation the processing of fruit and vegetables was not accounted for (see below).

In pesticide exposure assessment, the estimated distribution typically consists of many measurements below the minimum quantifiable pesticide residue concentration (limit of quantification or LOQ). This does not indicate the absence of pesticide residues in the sample, but only that the analytical method could not detect the possible amount of pesticide residue present. Samples with residue levels below the LOQ('non-detects') are often assigned either $0,1 / 2$ LOQ or LOQ corresponding to a lower, middle and upper bound (worst case) scenario. In general, the use of the middle bound scenario $(\mathrm{LOQ} / 2)$ is a good compromise. Therefore, results below the LOQ were replaced in this study by LOQ/2. A proper treatment of results below the LOQ may however, not be underestimated. Guidance on how to handle such data, is provided by the U.S. Environmental Protection Agency (U.S. EPA, 2000).

Exposure to the selected pesticide residues is given in Table 1, together with their EU-status, ADI and ARfD values and detection frequency. Fig. 1 presents an overview of the commodities contributing to the exposure at average consumption of the in this study most relevant pesticide residues.

The ten pesticides with the highest exposure level were selected for further study. As such, the effect of processing, age, gender and dietary pattern were studied in more detail and are presented in Table 2, 4 and 5, respectively. 
Table 1 Exposure (\% ADI) to pesticide residues based on the Belgian surveillance data 2008 (deterministic approach, middle bound scenario).

\begin{tabular}{|c|c|c|c|c|c|c|c|}
\hline Pesticide residue $^{\mathrm{a}}$ & Cat. $^{b}$ & EU status $^{c}$ & $\begin{array}{c}\text { Detection } \\
\text { frequency } \\
(\%) \\
\end{array}$ & $\begin{array}{c}\text { ADI } \\
\text { (mg/kg bw } \\
\text { per day) } \\
\end{array}$ & $\begin{array}{c}\text { ARfD } \\
\text { (mg/kg bw } \\
\text { per day) } \\
\end{array}$ & $\begin{array}{c}\text { Average } \\
\text { consumption }^{\mathrm{d}} \\
(\% \mathrm{ADI})\end{array}$ & $\begin{array}{c}\text { P97.5 } \\
\text { consumption }^{\mathrm{d}} \\
(\% \text { ADI }) \\
\end{array}$ \\
\hline Acetamiprid & $\mathrm{I}$ & Incl. & 2.8 & 0.07 & 0.1 & 0.0 & 0.2 \\
\hline Azoxystrobin & $\mathrm{F}$ & Incl. & 4.2 & 0.1 & n.d. ${ }^{\mathrm{e}}$ & 0.0 & 0.2 \\
\hline Boscalid & $\mathrm{F}$ & Incl. & 12.3 & 0.04 & n.d. & 0.1 & 0.8 \\
\hline Captan & $\mathrm{F}$ & Incl. & 3.6 & 0.03 & 0.1 & 0.3 & 1.9 \\
\hline Carbendazim & $\mathrm{F}$ & Incl. & 5.2 & 0.02 & 0.02 & 0.1 & 1.1 \\
\hline Chlorpropham & $\mathrm{H}$ & Incl. & 3.0 & 0.05 & 0.5 & 2.1 & 7.0 \\
\hline Chlorpyrifos & I & Incl. & 5.2 & 0.01 & 0.1 & 0.3 & 2.7 \\
\hline Cypermethrin & $\mathrm{I}$ & Incl. & 2.4 & 0.05 & 0.2 & 0.1 & 1.2 \\
\hline Cyprodinil & $\mathrm{F}$ & Incl. & 5.8 & 0.03 & n.d. & 0.1 & 1.2 \\
\hline Deltamethrin & I & Incl. & 2.3 & 0.01 & 0.01 & 0.2 & 1.5 \\
\hline Difenoconazole & $\mathrm{F}$ & Incl. & 7.9 & 0.01 & 0.2 & 0.3 & 2.3 \\
\hline Dimethomorph & $\mathrm{F}$ & Incl. & 3.7 & 0.05 & 0.6 & 0.1 & 0.4 \\
\hline Dithiocarbamates & $\mathrm{F}$ & Incl. & 9.8 & $0.05^{\mathrm{a}}$ & $x^{f}$ & 0.6 & 5.2 \\
\hline Fenhexamid & $\mathrm{F}$ & Incl. & 3.3 & 0.2 & n.d. & 0.0 & 0.4 \\
\hline Fludioxonil & $\mathrm{F}$ & Incl. & 4.5 & 0.37 & n.d. & 0.0 & 0.1 \\
\hline Imazalil & $\mathrm{F}$ & Incl. & 8.5 & 0.025 & 0.05 & 2.1 & 24.1 \\
\hline Imidacloprid & I & Incl. & 4.2 & 0.06 & 0.08 & 0.0 & 0.3 \\
\hline Iprodione & $\mathrm{F}$ & Incl. & 12.7 & 0.06 & n.d. & 0.2 & 2.6 \\
\hline Lambda-cyhalothrin & I & Incl. & 2.8 & 0.005 & 0.0075 & 0.4 & 3.6 \\
\hline Orto-phenylphenol & & Additif & 4.1 & 0.4 & - & 0.0 & 0.3 \\
\hline Pirimicarb & $\mathrm{I}$ & Incl. & 3.2 & 0.035 & 0.1 & 0.1 & 0.9 \\
\hline Prochloraz & $\mathrm{F}$ & $\begin{array}{l}\text { Max period of } \\
\text { grace: } 12 / 2011\end{array}$ & 2.6 & 0.01 & 0.1 & 0.8 & 9.9 \\
\hline Propamocarb & $\mathrm{F}$ & Incl. & 7.4 & 0.29 & 1 & 0.0 & 0.2 \\
\hline Spinosad & $\mathrm{I}$ & Incl. & 2.7 & 0.024 & n.d. & 0.1 & 0.8 \\
\hline Tebuconazole & $\mathrm{F}$ & Incl. & 3.7 & 0.03 & 0.03 & 0.1 & 0.7 \\
\hline Thiabendazole & $\mathrm{F}$ & Incl. & 6.1 & 0.1 & 0.1 & 0.3 & 2.9 \\
\hline Thiacloprid & I & Incl. & 2.6 & 0.01 & 0.03 & 0.2 & 2.1 \\
\hline Toldofos-methyl & $\mathrm{F}$ & Incl. & 2.8 & 0.064 & n.d. & 0.0 & 0.2 \\
\hline Triadimefon \& triadimenol & $\mathrm{F}$ & Triadimenol incl. & 2.3 & 0.05 & 0.05 & 0.1 & 0.2 \\
\hline
\end{tabular}

${ }^{a}$ Carbendazim and benomyl: sum of benomyl and carbendazim, expressed as carbendazim. Chlorpropham: chlorpropham and 3-chloraniline, expressed as chlorpropham. Cypermethrin: including other mixtures of constituent isomers (sum of isomers). Dithiocarbamates: expressed as CS2, including maneb, mancozeb, metiram, propineb, thiram and ziram. Pesticide sales of the dithiocarbamates in Belgium concerns mainly mancozeb and maneb. Therefore, the ADI of mancozeb and maneb was chosen as the reference. Pirimicarb: sum of pirimicarb and desmethyl, expressed as pirimicarb. Prochloraz: sum of prochloraz and its metabolites containing the 2,4,6-trichlorophenol moiety, expressed as prochloraz. Propamocarb: sum of propamocarb and its salt expressed as propamocarb. Spinosad: sum of spinosyn A and spinosyn D, expressed as spinosad. Triadimefon \& triadimenol: sum of triadimefon and triadimenol.

${ }^{\mathrm{b}}$ Category: I: insecticide; F: fungicide; $\mathrm{H}$ : herbicide.

${ }^{c}$ EU Pesticide Database: http://ec.europa.eu/sanco_pesticides/public/index.cfm\%3Fevent\%3Dactivesubstance.selection\%26a\%3D1 .

${ }^{\mathrm{d}}$ Based on the average residue concentration and the average consumption or the 97.5 th percentile of consumption respectively.

e Not determined.

${ }^{\mathrm{f}}$ depends on the molecule considered.

\section{Discussion}

\subsection{Exposure to pesticide residues on fruit and vegetables}

The chronic exposure of the Belgian consumer to pesticide residues through the consumption of raw fruit and vegetables appears to be relatively low in 2008. In most cases the exposure is more than one hundred times lower than the ADI. Based on the P97.5 of consumption, relatively high exposure values were observed for imazalil > prochloraz > chlorpropham and to a lesser extent for the dithiocarbamates, iprodione, difenoconazole, thiabendazole, chlorpyriphos, 1-cyhalothrin and thiacloprid (Table 1). 
Fig. 1. Contribution of different fruit and vegetables to the exposure (\% ADI) of pesticide residues based on the Belgian FASFC, 2008 surveillance data (deterministic assessment, average consumption, middle bound scenario, with and without processing factors PF, PF mentioned by the BfR (2009) = PF (1), and Juraske et al. $(2009)=P F(2)):(a)$ chlorpropham, (b) chlorpyriphos, (c) lambda-cyhalothrin, (d) difenoconazole, (e) dithiocarbamates, $(f)$ imazalil, $(g)$ iprodione, $(h)$ prochloraz, $(i)$ thiobendazole, $(j)$ thiocloprid.

a

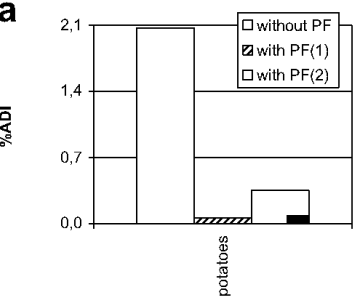

Chlorpropham

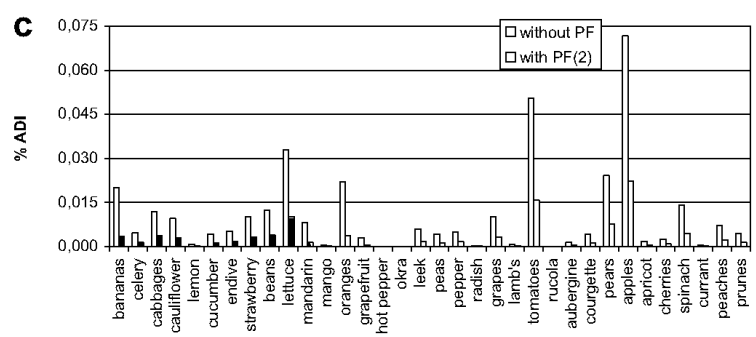

Lambda-cyhalothrin
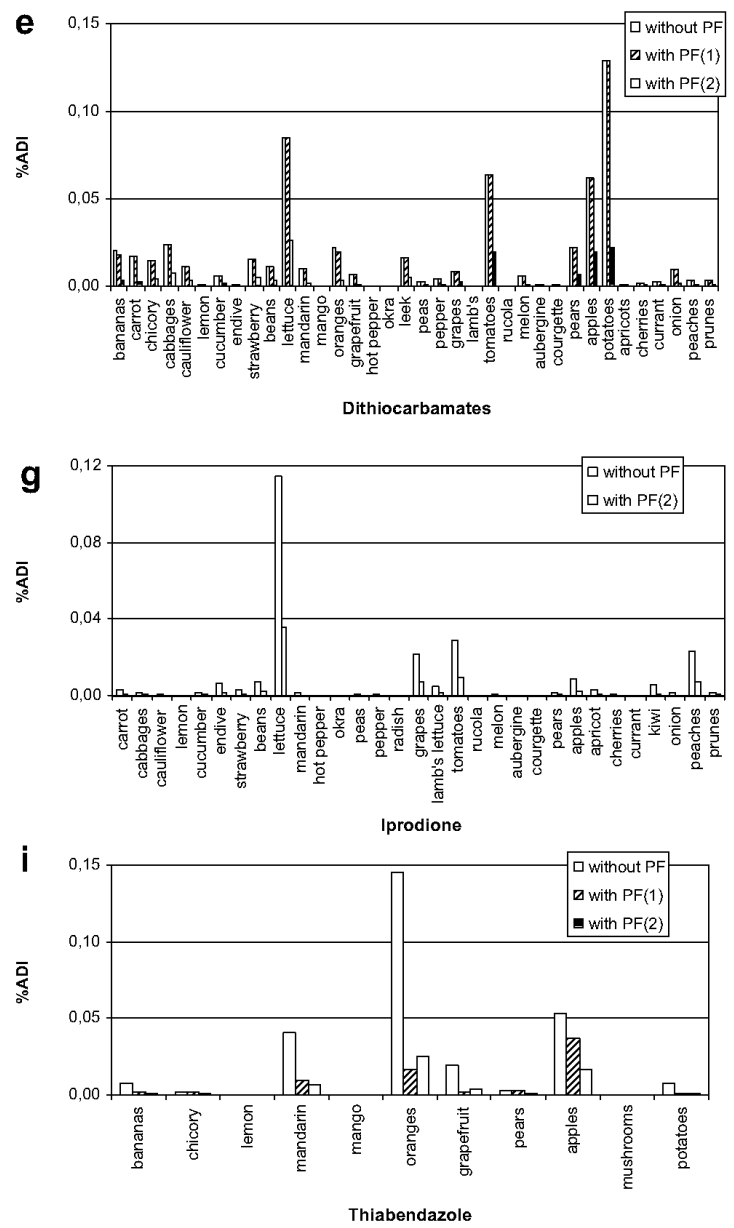
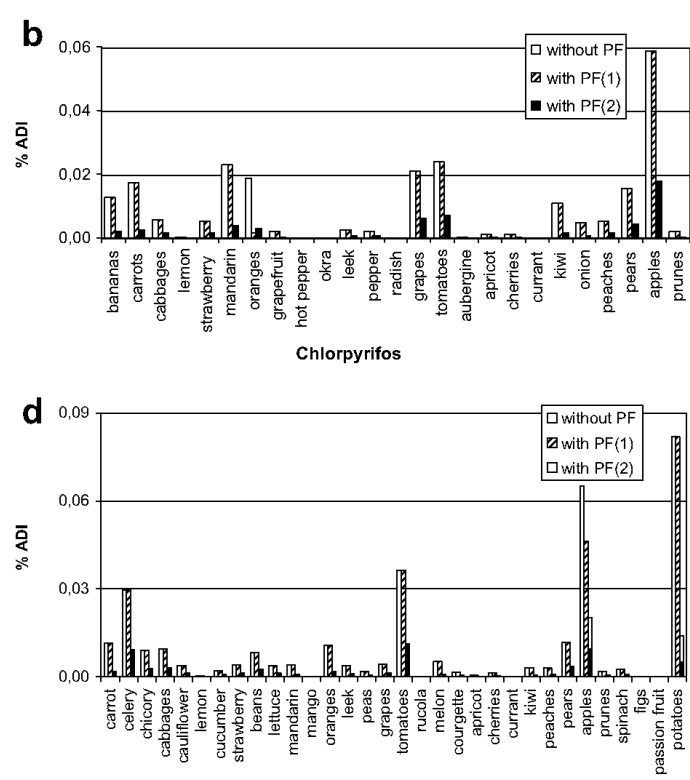

Difenoconazole

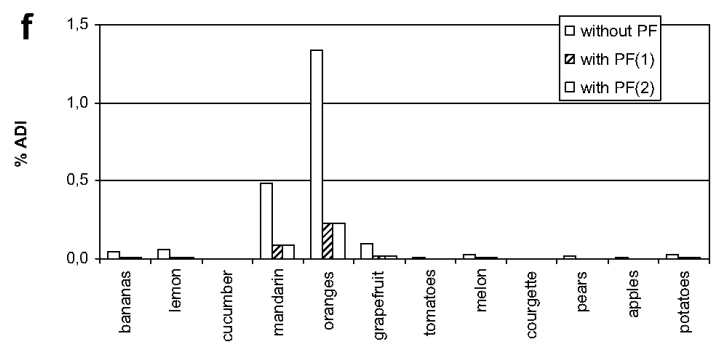

Imazalil
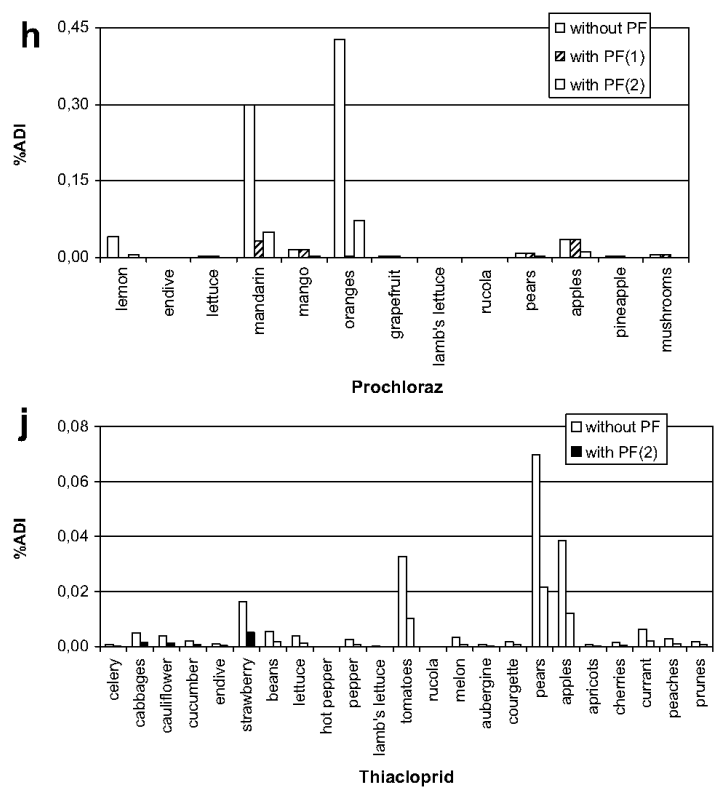

Table 2 Exposure (\%ADI) to selected pesticide residues, determined by the deterministic approach, with and 
without applying processing factors, and by the probabilistic approach.

\begin{tabular}{|c|c|c|c|c|c|c|c|c|c|}
\hline \multirow[t]{3}{*}{ Pesticide residue } & \multirow{2}{*}{\multicolumn{3}{|c|}{$\begin{array}{c}\text { Deterministic } \\
\text { Average consumption }\end{array}$}} & \multirow{3}{*}{$\frac{\text { Probabilistic }}{\text { Average exposure }}$} & \multicolumn{4}{|c|}{ Deterministic } & \multirow{3}{*}{$\begin{array}{c}\text { Probabilistic } \\
\text { P97.5 exposure }\end{array}$} \\
\hline & & & & & \multicolumn{3}{|c|}{ P97.5 consumption } & \multirow[t]{2}{*}{ High exposure $^{b}$} & \\
\hline & & $\mathrm{PF}(1)$ & $\mathrm{PF}(2)^{\mathrm{a}}$ & & & $\mathrm{PF}(1)$ & $\mathrm{PF}(2)$ & & \\
\hline Chlorpropham & 2.1 & 0.1 & 0.4 & 2.1 & 7.0 & 0.2 & 1.2 & - & 21.9 \\
\hline Chlorpyrifos & 0.3 & 0.2 & 0.1 & 0.3 & 2.7 & 2.5 & 0.7 & 0.8 & 1.3 \\
\hline Difenoconazole & 0.3 & 0.3 & 0.1 & 0.4 & 2.3 & 2.2 & 0.6 & 0.9 & 1.3 \\
\hline Dithiocarbamates & 0.6 & 0.6 & 0.2 & 0.6 & 5.2 & 5.1 & 1.4 & 2.1 & 2.5 \\
\hline Imazalil & 2.1 & 0.2 & 0.4 & 2.4 & 24.1 & 1.6 & 4.2 & 44.6 & 22.9 \\
\hline Iprodione & 0.2 & / & 0.1 & 0.2 & 2.6 & / & 0.8 & 2.2 & 2.0 \\
\hline Lambda-cyhalothrin & 0.4 & / & 0.1 & 0.4 & 3.6 & l & 1.0 & 1.2 & 1.3 \\
\hline Prochloraz & 0.9 & 0.1 & 0.2 & 0.9 & 9.9 & 1.0 & 1.7 & 19.4 & 6.3 \\
\hline Thiabendazole & 0.3 & 0.1 & 0.1 & 0.3 & 2.9 & 0.7 & 0.5 & 3.4 & 3.2 \\
\hline Thiacloprid & 0.2 & I & 0.1 & 0.2 & 2.1 & 1 & 0.7 & 2.3 & 1.0 \\
\hline
\end{tabular}

${ }^{a}$ PF (1) and PF (2): processing factors mentioned by the BfR (2009) and Juraske et al. (2009) respectively.

${ }^{\mathrm{b}}=\Sigma(\mathrm{P} 95$ exposure (consumers only) via the 2 food groups contributing the most + average exposure (total population) through the other food groups).

Imazalil is a systemic fungicide used to control a wide range of fungi on fruit, vegetables, and ornamentals. It is also used as a seed dressing and for postharvest treatment of citrus, banana, and other fruit to control storage decay. Prochloraz is a broad-spectrum fungicide forthe control or reduction of avariety of diseases mainly in wheat, barley, winter rye and rape. Chlorpropham is a plant growth regulator belonging to the $\mathrm{N}$ phenylcarbamate group of pesticides. It is mainly applied as sprouting inhibitor in potato storage. Potatoes, lettuce, tomatoes and apples are generally the most important contributors to the exposure to dithiocarbamates. Dithiocarbamates are widely used antisporulant (contact) fungicides that are very often associated with other fungicides.

Iprodione is a dicarboximide contact fungicide used to control gray mold, Monilia-rot (blossom and branch mortality), Sclerotinia stem rot and other fungal diseases in many cultures: fruits, vegetables, ornamental trees and plants, lawns and grass fields. It is a contact fungicide that inhibits the germination of spores and blocks the growth of the mycelium. Difenoconazole is a systemic broad-spectrum fungicide (triazole group) that protects the crop yield and quality through leaf and seed treatment. Chlorpyrifos is an organophosphate insecticide, often used against Red Scale, an important plague of citrus fruit. L-cyhalothrin is a pyrethroid insecticide and thiacloprid is a neonicotinoid insecticide.

The deterministic approach applied to determine the exposure is based on single point estimates that are used for each variable within the model (such as an average value or the 97.5th percentile). Advantages of this point estimate approach are that there is less need for extensive databases to support the input variables, that default standard assumptions can be used, that it is relatively easy to carry out, and that the single-risk estimate output is easy to understand and interpret. Due to its simplicity and its worldwide use and acceptance, the deterministic approach may be used as a first screening tool to identify possible pesticides that may pose a problem. If so, the probabilistic approach can then be applied to study if the point estimate outcome really gives reason for concern. In the probabilistic approach the variables are described in terms of distributions. In this way, all possible values for each variable are taken into account and each possible model outcome is weighted by the probability of its occurrence. Different techniques are available to calculate the outcome distribution, such as the Monte Carlo simulation. Advantages of this approach are that all available data and knowledge are used, that the exposure estimate is presented as a distribution, with each value having a probability attached to it, and that variability and uncertainty can be quantified (Ferrier, Nieuwenhuijsen, Boobis, \& Elliott, 2002; Leclerq et al., 2003; Vose, 2006).

Exposure values based on the probabilistic assessment approach are presented in Table 2 for imazalil, prochloraz, chlorpropham, the dithiocarbamates, iprodione, difenoconazole, thiabendazole, chlorpyriphos, 1cyhalothrin and thiacloprid.

The deterministically and probabilistically determined exposure values are not comparable since they are essentially based on different concepts. The deterministically obtained exposure values

are based on percentiles of consumption, whereas the probabilistically determined results are actual percentiles 
of exposure.

With respect to the group of high consumers, it is important to emphasize that the duration of the consumption survey affects the distribution of consumption data, particularly the upper percentiles. A brief survey often underestimates the consumption of less frequently consumed foods, but at the same time overestimates the quantities of frequently consumed foods. The nature of the survey method should thus be considered when interpreting results. High percentiles based on a one to two days consumption survey are often an overestimation compared to high percentiles obtained on the basis of a seven-day survey. Moreover, the reliability of the high percentiles also depends on the number of people or data on which their calculation is based. Percentiles that are calculated based on a limited amount of data, have a higher uncertainty and give only a rough indication of the higher consumption levels. According to Kroes et al. (2002), a high percentile P (P > P75) can only be evaluated with sufficient accuracy when the sample size $\mathrm{n}$ satisfies with $n(1-\mathrm{P}) \geq 8$. The minimum amount of data thus required for P95, P97.5 and P99 can be estimated as 160, 320 and 800 respectively. The same restrictions apply to the lower percentiles (EFSA, 2008).

Although the total exposure to all food categories is intuitively determined by the summation of the exposure through the different food categories, this results in a marked overestimation. By doing so, it is implicitly assumed that large portions of all foods (P97.5 of a consumption distribution) are consumed on 1 day or frequently by one person, and that all these foods are contaminated, which is highly unlikely. For a realistic estimate of short-term dietary exposure through multiple foods, a probabilistic approach is recommended (Hamilton et al., 2004). Nevertheless, when calculating the total exposure by the probabilistic approach, potential correlations between daily consumption rates of different food items need to be taken into account. As a pragmatic approach for assessing the long-term exposure, recorded days were considered independently, without discriminating between variation among individuals and variation among days (within individuals), resulting in a distribution of 'person-days'. The drawback of this approach is that it cannot be determined if few persons are at risk but each of them at many days, or that many persons are at risk but each of them only rarely (Pieters et al., 2005). Since the focus of the present study concerns mainly the intake of frequently exposed individuals, the intake was compared to the ADI rather than to the ARfD.

An approach proposed to partly circumvent the overestimation through summing point estimates across foods, is the summation of the P95 exposure (of consumers only) through the two food categories that contribute the most to the exposure with the average exposure (of the total population) via the other food groups. It is important to note that this method is only valid when the number of food categories is relatively small (e.g. 16 versus a larger number of 800) (EFSA, 2008). The exposure to chlorpropham is determined by the consumption of potatoes alone. Application of the proposed approach is therefore not useful. Regarding imazalil and prochloraz, the average exposure (LOQ/2) is mainly due to the consumption of citrus fruits, oranges and mandarins in particular. Potatoes and lettuce contribute the most to the average, middle bound exposure to the dithiocarbamates, lettuce and tomatoes for iprodione, potatoes and apples for difenoconazole, oranges and apples for thiabendazole, apples and tomatoes for chlorpyriphos and L-cyhalothrin, and apples and pears for thiaclo-prid (Fig. 1). Notice that the relatively high contribution of these commodities to the exposure is not necessarily due to their pesticide residue level, but might as well be ascribed to their common consumption.

The exposure of high consumers by application of this approach is listed in Table 2. For imazalil and prochloraz a significant increased intake is observed when applying the above outlined approach, indicating the potential impact of considering only consumers of food commodities that are eaten less frequently but at relatively high quantities such as oranges and mandarins.

Another source of uncertainty in the results is the linkage between the analysed and the consumed food items. Both databases, the food consumption survey and the pesticide surveillance database needed to be harmonised and categorized, and to be rendered compatible with regard to the considered food commodities. Also the processing of fruit and vegetables was not accounted for and will affect the outcome significantly as will be illustrated below. Other critical aspects are the replacement of residue data below LOQ. (which are unknown) by $\mathrm{LOQ} / 2$, and the sampling of commodities for pesticide residue analysis. Furthermore, the sampling for the surveillance program is not strictly according to an at random procedure, but rather based on a risk approach (directed or targeted sampling). The use of these data to estimate dietary exposure may thus lead to an overestimation of exposure. Nevertheless, surveillance programs are a convenient tool to perform an exposure assessment based on a vast amount of data.

\subsection{Processing of fruit and vegetables: processing factors}


The pesticide residue level is usually given for raw food commodities and not for the corresponding processed products. This is also the case in the FASFC surveillance database. MRL values are determined for the raw product as well. Pesticide residue levels in fruit and vegetables may however, change due to processing, such as washing, peeling, boiling, frying, fermentation, grinding. Ideally, a realistic risk assessment should consider the commodity as much as possible as consumed "at the table".

Depending on the process conditions and physicochemical properties of the pesticide residues, the residue concentration can increase or decrease during processing. The ratio of the residue level found in the processed commodity to the residue level in the raw product is given by a processing factor (PF). This is frequently a fixed value, which is multiplied with the measured residue concentration to obtain the actual concentration after processing. To reflect the variability of the PF, a distribution based value can be used instead, and PF may be sampled from a distribution with parameters specified by the user (probabilistic exposure assessment) (EFSA, 2007).

For a realistic estimation, PF should be accounted for. However, data on the effects of processing and consequently regarding PF are very limited. Another drawback is that when PF are available, they are an approximate value rendering the degree of overestimation uncertain. In addition, PF are often taken from literature, with incomplete information on how they were measured. Moreover, average PF are often estimated from a small number of measurements (e.g., 3) (EFSA, 2007). Mostly the conservative practice of ignoring PF is followed when assessing the exposure, even though this results more often than not in an overestimation of the exposure. To have an indication of the potential overestimation of the exposure, standard PF may be applied.

The effect of PF on the average and P97.5 exposure of various pesticide residues is given in Fig. 1 and Table 2. Hereto, PF given in a compilation of PF for pesticide residues in food and feed published by the German Federal Institute for Risk Assessment (BfR) were applied (BfR, 2009) (Table 3). Only washing and peeling were considered. In the absence of PF, sometimes default factors are applied. Based on a literature study, Juraske et al. applied as such a PF of 0.31 for washed products, of 0.17 for peeled products and of 0.13 for cooked products (Juraske et al., 2009). These default PF for washing and peeling were also applied for estimating the exposure.

Application of PF results in significantly lower exposure levels, with e.g., a decrease from $24 \%$ to $1.6 \%$ for the P97.5 exposure to imazalil. The high exposure to imazalil is mainly due to citrus. Residues on citrus are greatly reduced by removal of the skin. Similarly for e.g. chlorpropham, for which the exposure is determined by the consumption of potatoes. Potatoes are usually peeled and additionally boiled, resulting in an even lower exposure $(\mathrm{PF}$ for boiling $=0.33$, BfR, 2009).

\subsection{Exposure according to age and gender}

Children have a dietary pattern that differs significantly from the one of adults. Moreover, they have a relatively higher food consumption per $\mathrm{kg}$ body weight. Because at present, there are no detailed consumption data for children available in Belgium and because it can be assumed that the consumption of fruit and vegetables in Belgium is similar in a neighboring country, German consumption data for children were used. In 2001, a consumer survey was conducted in Germany on 816 infants and young children aged between 6 months and 5 years old. The survey was based on a six-day reporting by parents (BfR, 2005). Table 4 presents a rough estimate of the exposure of young children based on the average consumption data reported by the BfR for children between 2 and 5 years old and the FASFC, 2008 surveillance data, with and without applying default PF for washing and peeling. Although a significant reduction of the exposure estimates is observed when fruit and vegetables are washed/peeled, the exposure to imazalil, L-cyhalothrin and prochloraz remains relatively high when $\mathrm{PF}$ are taken into account, with respectively $53 \%, 36 \%$ and $26 \%$ of the ADI.

Whereas the exposure of children between 2 and 5 years old is higher compared to the general population $(>15$ years), the exposure to the selected pesticide residues seems to increase slightly according to the age groups $\leq 25$ years, between 25 and 65 years and $\geq 65$ years considered in the BFCS, which is consistent with the age-related (slight) increase observed with respect to the consumption of fruit and vegetables (data not given).

With respect to gender, the average fruit consumption of men is lower than the fruit consumption of women ( 99.4 versus $138 \mathrm{~g} /$ day), whereas the consumption of vegetables is similar for both sexes. This is more or less reflected by the exposure. The exposure to e.g. imazalil, thiabendazole and thiacloprid, residues for which fruit contributed the most to the exposure, is higher for women (P97.5 exposure $=26.1,3.0$ and 2.5\% of the ADI) compared to men (P97.5 exposure $=22.4,2.6$ and 1.7\% of the ADI). Regarding chlorpropham, for which the exposure is determined by potato consumption, the opposite is observed (mean exposure $=2.3$ and $1.8 \%$ of the 
ADI and P97.5 exposure $=7.5$ and $6.2 \%$ of the ADI for men and women respectively).

Table 3 Processing factors $(P F)$ reported in literature for the pesticide residue-commodity combinations considered in this study.

\begin{tabular}{|c|c|c|c|c|}
\hline \multirow[t]{2}{*}{ Pesticide residue } & \multicolumn{2}{|l|}{ BfR (2009) } & \multicolumn{2}{|l|}{ Juraske et al. (2009) } \\
\hline & $\begin{array}{l}\text { Commodity } \\
\text { (process) }\end{array}$ & $\mathrm{PF}(1)$ & Process: commodity & $\mathrm{PF}(2)$ \\
\hline Chlorpropham & Potatoes (peeling) & 0.027 & Peeling: potatoes & 0.17 \\
\hline \multirow[t]{2}{*}{ Chlorpyrifos } & Oranges (pulp) & 0.1 & $\begin{array}{l}\text { Peeling: banana, carrot, lemon, mandarin, orange, grapefruit, kiwi, } \\
\text { onion }\end{array}$ & 0.17 \\
\hline & & & Washing: remaining commodities considered & 0.31 \\
\hline \multirow[t]{2}{*}{ Difenoconazole } & Apples (washing) & 0.71 & $\begin{array}{l}\text { Peeling: carrot, lemon, mandarin, mango, orange, melon, kiwi, figs, } \\
\text { passion fruit, potatoes }\end{array}$ & 0.17 \\
\hline & & & Washing: remaining commodities considered & 0.31 \\
\hline \multirow[t]{3}{*}{ Dithiocarbamates } & Bananas (pulp) & 0.87 & $\begin{array}{l}\text { Peeling: banana, carrot, lemon, mandarin, mango, orange, grapefruit, } \\
\text { melon, potatoes, onion }\end{array}$ & 0.17 \\
\hline & Oranges (pulp) & 0.88 & & \\
\hline & & & Washing: remaining commodities considered & 0.31 \\
\hline \multirow[t]{5}{*}{ Imazalil } & Bananas (pulp) & 0.52 & Peeling: banana, lemon, mandarin, orange, grapefruit, melon, potatoes & 0.17 \\
\hline & Lemons (pulp) & 0.06 & & \\
\hline & Mandarins (pulp) ${ }^{\mathrm{a}}$ & 0.05 & Washing: remaining commodities considered & 0.31 \\
\hline & Oranges (pulp) & 0.045 & & \\
\hline & Grapefruit (pulp) & 0.07 & & \\
\hline \multirow[t]{2}{*}{ Iprodione } & / & & Peeling: carrot, lemon, mandarin, melon, kiwi, onion & 0.17 \\
\hline & & & Washing: remaining commodities considered & 0.31 \\
\hline \multirow{2}{*}{ Lambda-cyhalothrin } & / & & Peeling: banana, lemon, mandarin, mango, orange, grapefruit & 0.17 \\
\hline & & & Washing: remaining commodities considered & 0.31 \\
\hline \multirow[t]{3}{*}{ Prochloraz } & Lemons (pulp) & 0.01 & Peeling: lemon, mandarin, mango, orange, grapefruit, pineapple & 0.17 \\
\hline & Mandarins (pulp) & $0.11^{\mathrm{a}}$ & & \\
\hline & Oranges (pulp) & 0.01 & Washing: remaining commodities considered & 0.31 \\
\hline \multirow[t]{6}{*}{ Thiabendazole } & Bananas (pulp) & 0.31 & Peeling: banana, lemon, mandarin, mango, orange, grapefruit, potatoes & 0.17 \\
\hline & Lemons (pulp) & 0.39 & & \\
\hline & Mandarins (pulp) & $0.23^{\mathrm{a}}$ & Washing: remaining commodities considered & 0.31 \\
\hline & Oranges (pulp) & 0.11 & & \\
\hline & Apples (washing) & 0.68 & & \\
\hline & Potatoes (peeling) & 0.08 & & \\
\hline \multirow[t]{2}{*}{ Thiacloprid } & / & & Peeling: melon & 0.17 \\
\hline & & & Washing: remaining commodities considered & 0.31 \\
\hline
\end{tabular}

Table 4 Exposure of young children (2-5 years) to pesticide residues (\% ADI) based on the average residue concentration and consumption data reported by the BfR (2005) (deterministic approach, middle bound scenario).

\begin{tabular}{lcccc}
\hline Pesticide residue & \multicolumn{2}{c}{ Average consumption } & \multicolumn{2}{c}{ High consumption } \\
\cline { 2 - 5 } & \multicolumn{4}{c}{$\mathrm{PF}(2)^{\mathrm{b}}$} \\
\hline Chlorpropham & 3.2 & 0.5 & 16.8 & 2.9 \\
Chlorpyrifos & 2.6 & 0.7 & 25.2 & 6.1 \\
Difenoconazole & 2.2 & 0.6 & 17.8 & 4.7 \\
Dithiocarbamates & 3.0 & 0.8 & 43.9 & 11.7 \\
Imazalil & 28.0 & 4.8 & 310.1 & 53.0 \\
Iprodione & 1.2 & 0.4 & 30.4 & 9.2 \\
Lambda-cyhalothrin & 2.8 & 2.8 & 35.8 & 35.8 \\
Prochloraz & 10.5 & 1.9 & 151.0 & 26.2 \\
Thiabendazole & 3.9 & 0.8 & 33.7 & 5.9 \\
Thiacloprid & 1.4 & 0.4 & 30.2 & 9.3 \\
\hline
\end{tabular}

${ }^{a}$ i.e. P90, P95, P97.5 and maximal consumption, dependent on the percentile given by the BfR (2005). 


\subsection{Exposure of vegetarians and high fruit and vegetable consumers}

The general population consumes a number of food commodities that is rarely or never eaten by vegetarians (subgroups: pseudo-, lacto-, ovo-lacto, vegans and pescovegetarians), such as eggs, dairy and other products of animal origin. In addition, vegetarians consume certain products with more moderation than non-vegetarians, such as wine. On the other hand, vegetarians consume more fruits, vegetables, cereals and potatoes than the general population. The consumption of other products of vegetable origin is rather similar for both consumer groups (Van Audenhaege et al., 2009).

With regard to Belgium, there are only few data available regarding vegetarianism. A study conducted in 2001 showed that of the 1051 people surveyed $63 \%$ often eat meat, $27 \%$ only occasionally eat meat, $5 \%$ abandoned eating meat, $3 \%$ are occasionally and 2\% full-time vegetarian (EVA, 2010). In the BFCS 2004, no information was recorded regarding vegetarianism. Nevertheless, it is recommended to eat daily at least $300 \mathrm{~g}$ vegetables and 2 to 3 pieces of fruit (250-375 g) (VIG, 2005). With respect to the BFCS participants, at least $30 \%$ consumed $\geq 300 \mathrm{~g}$ vegetables per day and at least $7 \%$ consumed $\geq 300 \mathrm{~g}$ vegetables and $\geq 250 \mathrm{~g}$ fruit per day. The exposure of these consumer groups to the selected pesticides is given in Table 5.

As expected, the exposure to the selected pesticide residues is higher for large fruit and vegetable consumers and thus consequently also for vegetarians compared to the general population. Especially a high fruit consumption seems to affect the exposure. On the other hand, fruits are usually washed and peeled before consumption whereas the estimation did not take processing into account.

Vegetarians or persons consuming meat products less frequently, are in contrast, less exposed to residues in products of animal origin. Except for pesticides used as veterinary drugs or as biocides, the residues in food of animal origin are the indirect consequence of a (environmental) contamination of the feed. The levels are therefore in general lower than in foods of vegetable origin. The exceptions are lipophilic compounds, such as organo-chlorines (e.g. aldrin, lindane, DDT and their metabolites, which are currently banned) and a number of organophosphate compounds that concentrate in animal products (IPCS, 1996).

In the calculation it was assumed that the pesticide residue levels are the same in products consumed by the general population and those consumed by vegetarians or large fruit and vegetable consumers, though some studies demonstrated that people with a vegetarian lifestyle buy preferably organic or unsprayed products (Van Audenhaege et al., 2009). Based on various publications it can be assumed that these foods are less contaminated than conventional products (Pussemier, Larondelle, Van Peteghem, \& Huyghebaert, 2006). The higher consumption of foods with a 'potential risk' could thus be compensated by a potentially lower degree of contamination.

Finally, it should be noted that a vegetarian dietary pattern is generally associated with positive health effects, such as a lower risk for ischemic diseases by a low intake of saturated fatty acids. Additionally, a lower mortality rate was demonstrated for vegetarians compared to the general population (Key et al., 1999). Therefore, a riskbenefit analysis comparing the risk of exposure to pesticides to the beneficial, nutritional effects of fruit and vegetable consumption needs to be performed.

Table 5 Exposure (\% ADI) for high fruit and vegetable consumers to pesticide residues (deterministic approach, middle bound scenario).

\begin{tabular}{lcccccc}
\hline Pesticide residue & \multicolumn{3}{c}{ Average consumption } & \multicolumn{3}{c}{ P97.5 consumption } \\
\cline { 2 - 7 } & $\begin{array}{c}\text { Total } \\
\text { population }^{\mathrm{a}}\end{array}$ & $\begin{array}{c}\geq 300 \mathrm{~g} \\
\text { vegetables }\end{array}$ & $\begin{array}{c}\geq 300 \mathrm{~g} \text { vegetables } \\
+\geq 250 \mathrm{~g} \text { fruit }\end{array}$ & $\begin{array}{c}\text { Total } \\
\text { population }^{\mathrm{a}}\end{array}$ & $\begin{array}{c}\geq 300 \mathrm{~g} \\
\text { vegetables }\end{array}$ & $\begin{array}{c}\geq 300 \mathrm{~g} \text { vegetables } \\
+\geq 250 \mathrm{~g} \text { fruit }\end{array}$ \\
\hline Chlorpropham & 2.1 & 3.7 & 3.6 & 7.0 & 9.1 & 8.6 \\
Chlorpyrifos & 0.3 & 0.3 & 0.7 & 2.7 & 3.2 & 5.2 \\
Difenoconazole & 0.3 & 0.5 & 0.7 & 2.3 & 3.1 & 4.3 \\
Dithiocarbamates & 0.6 & 0.9 & 1.3 & 5.2 & 7.1 & 9.8 \\
Imazalil & 2.1 & 2.6 & 7.0 & 24.1 & 28.0 & 53.1 \\
Iprodione & 0.2 & 0.3 & 0.5 & 2.6 & 2.8 & 4.5
\end{tabular}




\begin{tabular}{|c|c|c|c|c|c|c|}
\hline Lambda-cyhalothrin & 0.4 & 0.5 & 0.9 & 3.6 & 4.9 & 7.0 \\
\hline Prochloraz & 0.8 & 1.0 & 2.6 & 9.9 & 11.9 & 19.4 \\
\hline Thiabendazole & 0.3 & 0.3 & 0.9 & 2.9 & 3.2 & 6.4 \\
\hline Thiacloprid & 0.2 & 0.3 & 0.6 & 2.1 & 2.5 & 4.1 \\
\hline
\end{tabular}

${ }^{a}$ as presented in Table 1, i.e. high fruit and vegetable consumers included.

\subsection{Risk assessment}

As already indicated in the introduction, detection frequency and the number of samples for which the MRL is exceeded, give an indication on residues and food commodities to prospect, but lack information to make concrete statements in terms of food safety. This can be illustrated by comparing e.g. difenoconazole with imazalil. For both pesticide residues the detection frequency was 8-9\% and only one MRL exceeding was observed (passion fruit and mandarin for difenoconazole and imazalil respectively). Nonetheless, a higher exposure was observed for imazalil compared to difenoconazole.

Based on results, the chronic intakes of the 29 considered pesticide residues are rather low compared to the ADI (mostly $<1 \%$ of ADI). The safety of the Belgian consumer (older than 15 years) thus seems to be generally under control in terms of (single) pesticide intakes through fruit and vegetable consumption. Nevertheless, some residues such as imazalil, prochloraz and chlorpropham need to be considered more closely given that for a high consumer (P 97.5) the intake can reach 24\%, 10\% and 7\% of the ADI respectively for a middle bound, conservative scenario. Application of PF mentioned in literature for washing and peeling on the other hand, lowers the intake to $4 \%, 2 \%$ and $1 \%$ respectively. Moreover, probabilistic analysis indicated that except for chlorpropham, the probability to exceed the ADI will be much lower than $0.001 \%$ when exposed to one of the selected pesticides. Other variables influencing the pesticide residue content, are amongst others storage, transportation, storage conditions and duration, interlaboratory variation and the analytical method used to measure the pesticide residue content.

With respect to children, based on German consumption data ( $2-5$ years old) the ADI was significantly exceeded for imazalil and prochloraz at a high or frequent fruit and vegetable consumption, with the exposure estimated as $314 \%$ and $162 \%$ of the ADI respectively. These results should however, be interpreted with care due to considerable uncertainty in the calculation. For instance, there is a lack of detailed information regarding children's consumption. In addition, the exposure estimation for high or frequent consumption was performed with P90, P95, P97.5 as well as with the maximum value for consumption, depending on the percentile reported in the German study for the considered food group. Application of PF (also involving uncertainty) results in a reduced exposure of $53 \%$ and $26 \%$ of the ADI for imazalil and prochloraz respectively. Children are a vulnerable group of fruit and vegetable consumers, who are due to their lower body weight, exposed to relatively higher pesticide residue levels. A more profound study regarding this consumer group is recommended.

Considering the acute exposure to pesticide residues, interpretation of exposure levels estimated in this study in terms of $\%$ of the ARfD will indicate the absence of acute risks, even for high consumers, given that the ADI values are lower than ARfD values (Table 1).

\section{Conclusion}

The FASFC controlled 1413 samples of fruit and vegetables in 2008. Pesticide residues were detected in $72 \%$ of the samples and standards were exceeded for $6 \%$ of the samples. Nevertheless, the exposure of the Belgian population to pesticide residues (15 years or older) appears to be under control, even when consuming frequently or high quantities of fruit and vegetables. For children there are however, indications that high consumption of fruit and vegetables could for some pesticides lead to an exceeding of the ADI. Since the calculation involved a number of important uncertainties, a more detailed study regarding this vulnerable group of consumers is however required.

\section{Acknowledgement}

The authors would like to acknowledge the Belgian Institute of Public Health for access to the consumption data, and the Scientific Committee of the Belgian Federal Agency for the Safety of the Food Chain (FASFC) for their guidance of this study. 
Published in : Food Control (2011), vol. 22, pp. 508-516.

Status : Postprint (Author's version)

\section{References}

BfR. (2005). BfR develops new dietary intake model for children, http://www.bfr. bund.de/cd/579 Information No. 016/2005.

BfR. (2009). BfR compilation of processing factors for pesticide residues, http://www.bfr.bund.de/cd/579 BfR Information No. 028/2009.

Devriese, S., De Backer, G., De Henauw, S., Huybrechts, I., Kornitzer, K., Leveque, A., et al. (2005). The Belgian food consumption survey: aims, design and methods. Arch. Public Health, 63,1-16.

EFSA. (2007). Opinion of the scientific panel on plant protection products and their residues on a request from the Commission on acute dietary intake assessment of pesticide residues in fruit and vegetables. The EFSA Journal, 538, 1-88.

EFSA. (2008). Concise European food consumption database. http://www.efsa.europa.eu/en/datex/datexfooddb.htm.

European Community. (2002). Commission directive 2002/63/EC of 11 July 2002 establishing Community methods of sampling for the official control of pesticide residues in and on products of plant and animal origin and repealing Directive 79/700/EEC. Official Journal of the European Communities, L187, 30-43. http://eur-lex.europa.eu/LexUriServ/LexUriServ.do?uri=OJ:L:2002:187:0030: 0043:EN:PDF

Eurostat. (2009). EC European statistical database. Food: From farm to fork statistics_- Sales of plant protection products [food_in_apest1] Last update: 09-04-2010. http://epp.eurostat.ec.europa.eu/portal/page/portal/eurostat/home.

EVA. (2010). Ethisch Vegetarisch Alternatief, Veelgestelde vragen (Vegetarisme Algemeen).

http://www.vegetarisme.be/index.php\%3Fltemid\%3D108\%26id\%3D18\%26option\%3Dcom_content\%26view\%3Darticle/.

FASFC. (2008). Pesticide residue monitoring in food of plant origin - Belgium 2008. Results of the official controls in accordance to Regulation (CE) N³96/2005 and Commission Recommendation 2008/103/EC. http://www. favvafsca.fgov.be/thematischepublicaties/_documents/2008_Belgium-summary.pdf.

Ferrier, H., Nieuwenhuijsen, M., Boobis, A., \& Elliott, P. (2002). Current knowledge and recent developments in consumer exposure assessment of pesticides: a UK perspective. Food Additives \& Contaminants, 19(9), 837-852.

Hamilton, D., Ambrus, A., Dieterle, R., Felsot, A., Harris, C., Petersen, B., et al. (2004). Pesticide residues in food — acute dietary exposure. Pest Management Science, 60(4), 311-339.

IPCS. (1996). Persistent organic pollutants: an assessment report on DDT, aldrin, dieldrin, endrin, chlordane, heptachlor, hexachlorobenzene, mirex, toxaphene, polychlorinated biphenyls, dioxins and furans. http://www.pops.int/documents/ background/assessreport/en/ritteren.pdf.

Juraske, R., Mutel, C., Stoessel, F., \& Hellweg, S. (2009). Life cycle human toxicity assessment of pesticides: comparing fruit and vegetable diets in Switzerland and the United States. Chemosphere, 77(7), 939-945.

Key, T., Fraser, G., Thorogood, M., Appleby, P., Beral, V., Reeves, G., et al. (1999). Mortality in vegetarians and nonvegetarians: detailed findings from a collaborative analysis of 5 prospective studies. Am J Clin Nutr., 70(3 Suppl), 516S-524S.

Kroes, R., Muller, D., Lambe, J., Löwik, M., van Klaveren, J., Kleiner, J., et al. (2002). Assessment of intake from the diet. Food and Chemical Toxicology, 40, 327-385.

Lederq, C., Arcella, D., Armentia, A., Boon, P., Kruizinga, A., Gilsenan, M., \& Thompson, R. (2003). Development of databases for use in validation studies of probabilistic models of dietary exposure to food chemicals and nutrients. Food Additives \& Contaminants, 20(Suppl. 1), S27-S35.

MAFF. (2000). Annual report on the Working Party on pesticide residues: 1999. Supplement to the pesticides Monitor 2000, Ministry of agriculture Fisheries and food (MAFF), Pesticides Safety Directorate, Health \& Safety Executive. London (England): MAFF Publications, http://www.pesticides.gov.uk/uploadedfiles/Web_Assets/PRC/WPPR_1999.pdf.

Maudoux, J. -P., Saegerman, C., Rettigner, C., Houins, G., Van Huffel, X., \& Berkvens, D. (2006). Food safety surveillance through a risk based control programme: approach employed by the Belgian Federal agency for the safety of the food chain. Veterinary Quarterly, 28(4), $140-154$

Pieters, M., Ossendorp, B., \& Slob, W. (2005). Probabilistic modelling of dietary intake of substances. The risk management question governs the method. http://rivm.openrepository.eom/rivm/bitstream/10029/7301/1/320011001.pdf RIVM report 320011001/2005.

Pussemier, L., Larondelle, Y., Van Peteghem, C, \& Huyghebaert, A. (2006). Chemical safety of conventionally and organically produced foodstuffs: a tentative comparison under Belgian conditions. Food Control, 17(1), 14-21.

U.S. EPA. (2000). Assigning values to non-detected/non-quantified pesticide residues in human health food exposure assessments, http://www.epa.gov/ pesticides/trac/science/trac3b012.pdf.

Van Audenhaege, M., Héraud, F, Menard, C., Bouyrie, J., Morois, S., Calamassi-Tran, G., et al. (2009). Impact of food consumption habits on the pesticide dietary intake: comparison between a French vegetarian and the general population. Food Additives \& Contaminants, 26(10), 
Published in: Food Control (2011), vol. 22, pp. 508-516.

Status : Postprint (Author's version)

$1372-1388$.

VIG. (2005). De actieve voedingsdriehoek. Vlaams Instituut voor Gezondheidspromotie.

http://www.vig.be/content.asp\%3Fnav\%3Dthemas_voeding\%26selnav\%3D205\%23.

Vose, D. (2006). Risk analysis - A quantitative guide (2nd ed.). West Sussex (England): John Wiley \& Sons, Ltd.

WHO. (2003). GEMS/food regional diets (regional per capita consumption of raw and semi-processed agricultural commodities), http://www.who.int/foodsafety/ publications/chem/regional_diets/en/. 